\title{
THE PAST, PRESENT, AND FUTURE OF DENTISTRY THROUGH LENSES: A SHORT COMMUNICATION
}

\author{
SUMAN MUKHERJEE ${ }^{1 *}$, SHARMISTHA DASGUPTA ${ }^{2}$ \\ ${ }^{1}$ Department of Periodontics and Oral Implantology, Periodontist and Oral Implants Specialist at Arogya Bardini Polyclinic, Puruliya, \\ West Bengal, India. ${ }^{2}$ Department of Periodontics and Oral Implantology, RHT Multispeciality Clinic, New Delhi, India.
}

Email: smjee234@gmail.com

Received: 22 January 2021, Revised and Accepted: 26 February 2021

ABSTRACT

This article gives a contemplative viewpoint on the lenses in dentistry.

Keywords: Lenses, Lasers, Microscope, COVID, Endodontics, Periodontics, History.

(C) 2021 The Authors. Published by Innovare Academic Sciences Pvt Ltd. This is an open access article under the CC BY license (http://creativecommons.org/ licenses/by/4.0/) DOI: http://dx.doi.org/10.22159/ajpcr.2021v14i4.40857. Journal homepage: https://innovareacademics.in/journals/index.php/ajpcr

\section{INTRODUCTION}

Microscopes and microorganisms have a long and deep dive in history.

The evolution of the present understanding of the disease and its intricate pathway of pathogenesis is a glimpse of the importance of a microscope in the investigation at the cellular level. The benefits of microscopes range from being a simple tool to study and identify the complex structures of microorganisms, to being an aid in precision skills and treatment. The story of the evolution of the microscope in dentistry has been fascinating.

Today, a simple combination of lenses forms a magneto-optical microscope. A confocal microscope can be modified for dark-field imaging. The progress in technology and robust evolution of lenses made it a robust tool for the dental profession in the present and future.

Few of the field in dentistry that has immensely benefited and taken advantage of lenses, it is implant dentistry, periodontics, and endodontics. Implant imaging and planning have been revolutionized by the use of scanning microscopes, Micro computed tomography (CT) [1], and cone-beam CT aided microscope [2]. It gives 3-D high-density nondestructive images of the tooth and surrounding structures. Digital radiography has become a precise, convenient source to diagnose the minutest of changes in hard tissue.

Microsurgery, minimally invasive surgery, and operative treatment under loupes and the surgical microscope are reforming dentistry. Periscope's (also known as a dental endoscope) aids in the detection of unseen bleeding spots during root canal therapy, excision of pulp polyps, and enhanced visibility during root instrumentation. Hence, periscopes offers dentists the cutting edge in early diagnosis of pathogenesis with superior technical support for precision treatment.

Lasers are one of the foremost gifts of lenses to dentistry. Laser treatment is gaining popularity because it is clean, bloodless, and less painful. Furthermore, minor treatments using a laser-like frenectomy, gingivectomy, and pocket debridement gives superior patients satisfaction. Although, the benefits of laser compared to most conventional treatment is questionable, its role as an adjunct is beneficial in surgeries.
In endodontics, lasers devices have diverse applications, such as dental pulp testing by laser Doppler flowmetry, direct pulp capping, vital pulpectomy, disinfection of root canals, root canal cleaning, root canal shaping, and removal of foreign bodies from root canals, including fractured files or gutta-percha. When lasers are used for granulation tissue curettage, perforation repair, or apicoectomy, it would be desirable to use them under a microscope. Further, laser filters while performing clinical procedures with lasers have unfurled further scopes for safety, accuracy, and clarity in laser dentistry [3].

The microscope has a key role to play in cancer research, its early detection, and prevention. As the incidence and prevalence of oral cancer and precancerous lesions are escalating, mobile microscopy is capturing more interest. It is a screening tool that can be used by minimally trained technicians in low resource settings. This development will benefit a developing nation such as India, where the cost, feasibility, and accessibility to testing facilities are limited [4].

In the recent pandemic of coronavirus disease, a scanning electron microscope became an indispensable tool to isolate, study, and observe the development of coronavirus in human fetal diploid lung cells. Viruses cannot be cultured but can be identified under a highpower microscope. As such, research is being done for easy chairside identification of viruses. Simple microscopes are already used by oral medicine and dermatology to ease oral lesions identification and detection.

Chairside tests are gaining popularity for their ease and convenience, as such we already have a candidiasis chairside test based on direct microscopy.

Whenever we get stuck in diagnosis in dentistry, we can search for clues under the microscope. This is not just a popular opinion, but a new path for further understanding and results. There are so many complex diseases such as systemic disease along with local lesions which can make the treatment planning very complex. The right thing would be a thorough knowledge of what we are dealing with. Blood investigations and microscopic evaluation will add more clarity and better assistance for any simple dental treatment. Lenses in general and microscopes, in particular, have been a forgotten dilemma in dentistry. While lasers have been gaining popularity and acceptance, the millennials will be more benefited by taking advantage of every ply of lenses now than ever. 


\section{ACKNOWLEDGMENT}

Nil.

\section{AUTHORS CONTRIBUTION}

Dr. Suman Mukherjee had written the manuscript. Dr. Sharmistha Dasgupta gathered data, solely did the editing, revision, and correction of the manuscript.

\section{CONFLICTS OF INTERESTS}

Nil.

\section{AUTHORS FUNDING}

Nil.

\section{REFERENCES}

1. Çapar İD, Gök T, Uysal B, Keleş A. Comparison of microcomputed tomography, cone beam tomography, stereomicroscopy, and scanning electron microscopy techniques for detection of microcracks on root dentin and effect of different apical sizes on microcrack formation. Microsc Res Tech 2019;82:1748-55.

2. Yang YM, Guo B, Guo LY, Yang Y, Hong X, Pan HY, et al. CBCTaided microscopic and ultrasonic treatment for upper or middle thirds calcified root canals. Biomed Res Int 2016;2016:4793146.

3. Saegusa H, Watanabe S, Anjo T, Ebihara A, Suda H. Safety of laser use under the dental microscope. Aust Endod J 2010;36:6-11.

4. Skandarajah A, Sunny SP, Gurpur P, Reber CD, D'Ambrosio MV, Raghavan $\mathrm{N}$, et al. Mobile microscopy as a screening tool for oral cancer in India: A pilot study. PLoS One 2017;12:e0188440. 